\title{
Finite element analysis of aircraft tire behaviour under overloaded aircraft landing phase
}

\begin{abstract}
The effect of increasing aircraft landing weight on the tire during aircraft landing phase was investigated in this paper. 3D finite element tyre model was created and simulated using finite element tool (LS-DYNA). The landing scenario of $3.05 \mathrm{~m} / \mathrm{s}$ velocity as specified by European Aviation Safety Agency (EASA) standards was not specifically met but the modelling produce approximate landing scenario of $2.8 \mathrm{~m} / \mathrm{s}$ velocity. The landing velocity was one directional and it was modelled using the Boundary prescribed motion method in LS-DYNA. Applying 77300Kg (referenced landing weight of Airbus A321NEO) as initial load case, maximum von-mises stress of $270 \mathrm{MPa}$ was obtained for the modelled aircraft tire. Subsequent increase of the initial aircraft landing weight led to stress propagations across the tire model with increasing maximum von-mises stress value up to $20000 \mathrm{MPa}$ upon an applied force of $150000 \mathrm{Kg}$ exerted by the aircraft landing weight. It was observed that the tire had started undergoing deformation at aircraft landing weight above the initial weight of $114000 \mathrm{Kg}$ with maximum von-mises of $4360 \mathrm{MPa}$ at the point of landing, but this deformation which was characterize by cracks due to wear and tear effect of the tire thread had intensified by tearing the tire at aircraft landing weight of $126000 \mathrm{Kg}$ with maximum von-mises stress of $9620 \mathrm{MPa}$. However at a landing weight of $150000 \mathrm{Kg}$, von-stress distribution $(20460 \mathrm{MPa})$ across the tire structure was relatively high and this led to increase in the tearing/blowout effect on the tire. Hence, airlines should effect intensive checking routine in order to prevent the operation of overloaded aircraft, as this may not only damage the aircraft tire or its assembly but can result in unforeseen airplane crash.
\end{abstract}

Keywords: aircraft weigh, aircraft phase, tire, simulation, wear, stress deflection, traction wave
Volume 2 Issue I - 2018

\author{
Ikpe Aniekan Essienubong, Owunna \\ Ikechukwu, Satope Paul \\ Department of Mechanical Engineering, Coventry University, UK \\ Correspondence: Ikpe Aniekan Essienubong, Masters \\ in Coventry University, Mechanical Engineering, Tel \\ +2348I25434634, Email ikpeaniekan@gmail.com
}

Received: January 16, 2018 | Published: February 26, 2018

\section{Introduction}

Aircraft tires are designed to travel at high speeds to support heavy loads which may include passengers, luggage and the entire weight of the aircraft. ${ }^{1}$ Determining the maximum allowable weight of an aircraft can be achieved through elaborative design considerations. In this case, the aircraft manufacturer ensures that empty weight of the aircraft and location of its Empty Weight Center of Gravity (EWCG) is provided to the aircraft operator before the aircraft leaves the factory. The aircraft empty weight usually include the structural framework, power generation system, all fixed and rotating parts, fixed ballast, passenger seats and life vests, close system fluid etc. and does not include the payload (Cargo, Passenger, luggage), fuel, oil etc. ${ }^{2}$ However, to determine the Operational Empty Weight (OEW), the Manufacturer's Empty Weight (MEW) and Operator's item are summed up together, of which the operator's item include fluids required for aircraft operation, catering accessories, flight crew members and their luggage etc. Furthermore, addition of the OEW to the payload would yield the Zero Fuel Weight (ZFW) which is the gross weight of the aircraft and its overall content subtracted by the total weight of used fuel on board. If the total fuel required for a trip is added to the ZFW, the Actual Gross Weight (AGW) would be obtained. ${ }^{3}$ To arrive at the actual aircraft landing weight which is very essential in this study, take-off weight is subtracted by Trip fuel which is the required amount of fuel from brake release on takeoff at the departure aerodrome to the landing touchdown at the destination aerodrome. Considering the effect of aircraft weight on the tire during landing, the tire may flex linearly and radically, thereby, causing high stress deflection, higher tensile and compressive forces as well as increased shear stress depending on the landing impact and gross weight of the aircraft. ${ }^{4,5}$ Aircraft tires are subjected to intense loading during its landing phase and it is essential to ensure that the structural integrity of the tire is not undermined during this phase of the flight. ${ }^{6}$ As the tire skids and the surface contacting the runway tries to return to its normal shape, inertia and centrifugal force causes it to distort and form a traction wave during landing. Guo et al. ${ }^{7}$ considered the landing scenario of an aircraft as an important scenario in the design of a tyre and wheel assembly for use in any aircraft, as such scenario can help simulate the amount of impact load on the tire before failure. According to Persson, ${ }^{8}$ the friction force generated between the tire and the asphalt surface in the aircraft landing phase is related to the internal friction of the rubber. Hence, the hysteretic friction function can be derived by gripping and sliding of the rubber over a coarse surface. These oscillating forces can result in energy dissipation, thereby, causing heating of the tire material to a level where smoke is generated. However, as a result of high deflection of the tire section under intense loading, the tensile forces on the outer plies may be 
higher than those on the inner plies. ${ }^{9,10}$ Also, as a result of the force gradient from outer to inner plies of the tire, shear forces may develop between the layers of the rubber, and overloading a tire with excessive aircraft weight may as well increase these shear forces, thus rapidly hampering the longevity of an aircraft tire. ${ }^{11}$ Reid et al. ${ }^{12}$ suggested that computer models have been used effectively in recent times to compute the interaction between aircraft landing phase, the tire and the asphalt surface, in which the structural properties (material and thickness) of the aircraft tire is adjusted to minimize the risk of tire blowout upon landing with excessive aircraft load. ${ }^{13}$ This study aims at investigating the effects of an aircraft landing weight on the tire, using Finite Element Method (FEA) to create and simulate the tire model for different aircraft landing weights.

\section{Theoretical evaluation}

Tire rolling resistance coefficients (RRC) is the force resisting the motion when an aircraft tire rolls on asphalt surfaces during landing. This is given by the following equation 1 and 2;

$$
\begin{gathered}
R R C_{1}=\frac{F_{x}}{F_{z}} \\
R R C_{2}=\frac{M_{y}}{r} / F_{z}
\end{gathered}
$$

Where, $\mathrm{F}_{\mathrm{x}}$ is the longitudinal forces, $\mathrm{F}_{\mathrm{z}}$ is the vertical loads, $\mathrm{r}$ is the rolling radius, $\mathrm{M}_{\mathrm{y}}$ is the rolling resistance moment and $\mathrm{RRC}$ is the tire Rolling Resistance Coefficients.

Depending on the severity of landing impact and tire rolling resistance during an aircraft landing phase, the overloaded aircraft tire in attempt to overcome the forces exerted on it by the aircraft may be subjected to certain conditions such as logarithmic decrement $(\delta)$ given by equation 3 ;

$$
\delta=\ln \left(\frac{\theta_{1}}{\theta_{2}}\right)
$$

Where the first two amplitudes $\left(\Theta_{1}\right.$ and $\left.\Theta_{2}\right)$ after landing are recorded with respect to the times ( $\mathrm{t} 1$ and $\mathrm{t} 2$ ) between these amplitudes.

Considering the time between amplitudes, the undamped $\left(\omega_{n r}\right)$ and damped $\left(\omega_{d r}\right)$ periods of vibration is given by equation 4 and 5 respectively;

$$
\begin{gathered}
\omega_{n r}=\frac{2 \pi}{\tau_{d} \sqrt{1-\xi_{b z}^{2}}} \\
\omega_{d r}=\frac{2 \pi}{\tau_{d}}
\end{gathered}
$$

Where, $\tau_{d}$ is the damped period of vibration given by equation 6 ;

$$
\tau_{d}=t_{2}-t_{1}
$$

The over damped condition may be due to the upward and downward motion of the aircraft during landing. The energy will decay much like an under damped mechanical systems and the damping constant can be obtained by calculating the difference in oscillation amplitudes as time progresses. In this case, the damping ratio $(\xi)$ is given by equation 7 ,

$$
\xi=\frac{\delta}{\sqrt{4 \pi^{2}-\delta^{2}}}
$$

The $t_{1}$ and $t_{2}$ represents the time of first and second peak for every damping period. Taking account of the undamped and damped periods of vibration, the critical damping constant $\left(\mathrm{C}_{\mathrm{c}}\right)$ is given by equation 8 ;

$$
C_{c}=2 \times I_{b y} \times \omega_{n r}
$$

Where $\mathrm{I}_{\mathrm{by}}$ is the moment of inertia of the airplane tire belt.

Since the aircraft at the point of landing is subjected to periodic oscillation, the amplitude (A) which is the maximum displacement from equilibrium can be determine by rearranging the relationship expressed in equation 9 ;

$$
x=\mathrm{A} \sin (\omega t+\phi)
$$

From equation 9, the amplitude (A) can be expressed as;

$$
\mathrm{A}=\frac{x}{\sin (\omega t+\phi)}
$$

Where, $\mathrm{x}$ is the displacement $(\mathrm{m}), \mathrm{A}$ is the amplitude $(\mathrm{m}), \omega$ is the angular frequency ( $\mathrm{rad} / \mathrm{s}), \mathrm{t}$ is time (s) and $\phi$ is the phase shift (radians). The frequency (f) in terms of angular velocity is given by equation 11 ;

$$
f=\frac{\omega}{2 \pi}
$$

Considering the oscillation amplitude and their effects, the aircraft tire may be prone to wear, crack propagation and critical tearing energy which is the energy released per unit area of crack surface growth as given by equation 12 ;

$$
T=-\left(\frac{\partial W}{\partial A}\right)_{\ell}
$$

Where, $T$ is the tearing energy (or energy release rate), $W$ is the elastic energy stored in the aircraft tire, $A$ is the area of one fracture surface of the crack and the suffix $\ell$ denotes differentiation with constant displacement of the boundaries over which forces are applied. Hence, the interaction between the aircraft weight and the responding behaviour of the tire is given by the relationship in equation 13;

$$
W_{t}=\frac{\text { Applied vertical load }}{\text { Measure deflection }}
$$

In this case, severe loading condition of the aircraft during landing may cause the aircraft tire to deflect, and this deflection depending on its severity may build up high stresses and cracks on the tire. However, this can subject the tire to intensive wear, distortion and tear effect if the overdamping frequency is continuous or if the vertically applied load in terms of the aircraft weight is excessive. ${ }^{14}$ The distortion can be determined using von-mises theory which helps in predicting yielding of a material when subjected to critical loading conditions. The yielding criteria for von-mises stress can be expressed by the yield stress relationship in equation 14;

$$
\sqrt{\frac{1}{2}\left(\sigma_{x}-\sigma_{y}\right)^{2}+\frac{1}{2}\left(\sigma_{x}-\sigma_{z}\right)^{2}+\frac{1}{2}\left(\sigma_{y}-\sigma_{z}\right)^{2}+3\left(\tau_{x y}+\tau_{x z}+\tau_{y z}\right)^{2}}=\sigma_{Y}
$$


Where $\sigma_{x}, \sigma_{y}, \sigma_{z}=$ Principal stresses in corresponding direction, $\tau_{x y}, \tau_{x z}, \tau_{y z}=$ Shear stresses in corresponding planes and $\sigma_{Y}=$ yield stress.

\section{Materials and methods}

Aircraft tire was modeled using LS-DYNA to address the effect of increasing aircraft landing weight on tire. Simulating the model shown in Figure 1, it was expected that the landing forces which is directly proportional to the critical stresses would cause further changes in the geometry of the tire. The tire computer model would make use of a computation method based on the finite element analysis technique and would use an explicit solver in order to extract the corresponding stresses resulting from the loading condition. The justification for adopting this computational method is due to the dynamics of interaction (between the aircraft weight, the tire and the asphalt surface) in the aircraft landing phase and stress wave propagation across the tire framework (Figure 1).

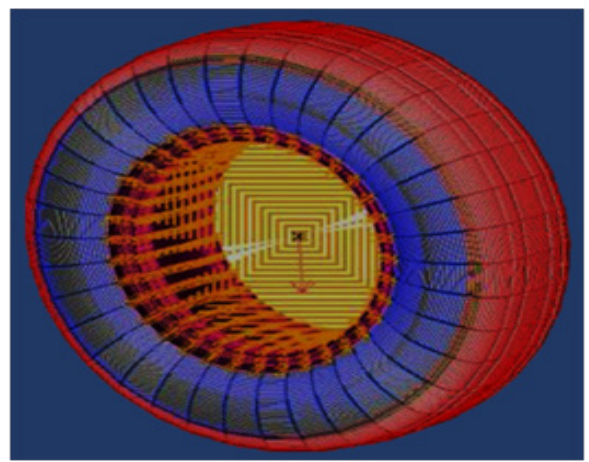

Figure I Aircraft Tire Model.

Furthermore, reference maximum landing weight $(77,300 \mathrm{~kg})$ of Airbus A321NEO was used as the initial loading criteria, ${ }^{15}$ followed by subsequent loading values at increasing intervals. That is, when the loads (maximum aircraft landing weight) were applied, oscillation of the tire model occurred and each amplitude of oscillation was noted accordingly. However, three aircraft landing scenarios considered for this study included no contact with ground, point of landing and after landing but this study is focused on the point of landing (or point of contact with the ground) where the aircraft tire had full contact with the ground as presented in Figure 2.

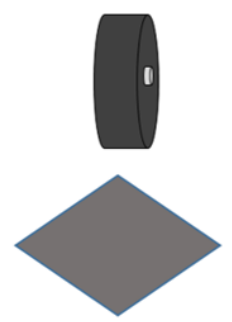

(a) No contact with ground

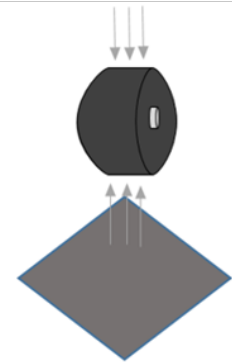

(b) Point of Landing

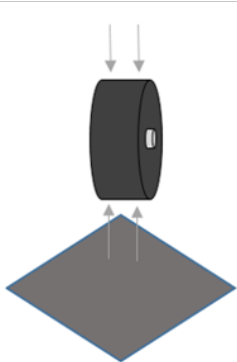

(c) After landing
Figure 2 Aircraft Landing Scenarios Considered for this Study.
Figure $2 \mathrm{~A}$ represents a scenario where the aircraft has not yet landed. In addition, Figure 2B represents a scenario where the aircraft has just landed, while, Figure $2 \mathrm{C}$ represent an empty aircraft weight where the aircraft has landed with passengers and cargo evacuated.

\section{Modelling software}

Cambridge Engineering Software (CES), 2016 version was used to select the grade of rubber material for the tire model using. The modelling and simulation of the aircraft tyre were carried out using the explicit finite element software (LS-DYNA). Explicit finite element analysis can solve problems that require small time step in calculating the properties and the geometry of a body at a particular time during a simulation. This is possible because explicit analysis uses central difference method and return mapping algorithm for solving explicit problems and thus the expensive matrix inversions and numerical iteration can be avoided in calculating the properties or geometry of a material at any particular time. LS-DYNA was chosen because it has the advantage of being a very good tool for explicit solver for dynamic transient analysis (those including blasting and high speed impact situations). ${ }^{16}$ The LS-DYNA PRIMER software and its associated packages were used in conjunction with the High Performance Computer (HPC). The analyses of the results generated were carried out using the LS-PREPOST software.

\section{Results and Discussion}

Stress variation on tyre model with respect to increasing aircraft landing weight was simulated and the maximum and minimum von-mises stresses were recorded as shown in Table 1. Figure 3 is a graphical illustration of the von-mises stress values in response to the aircraft landing weight. Figures 4-9 show the stress plot and their effects on the geometry of the aircraft tire at increasing aircraft weight.

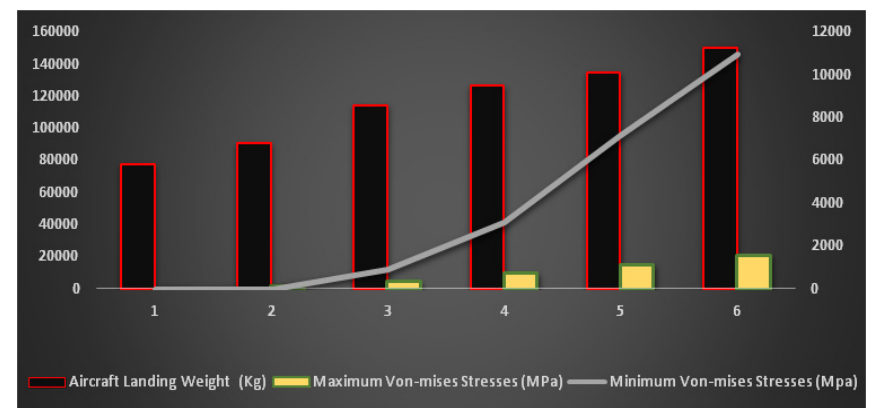

Figure 3 Von-mises Stress Values in Response to the Aircraft Landing Weight.

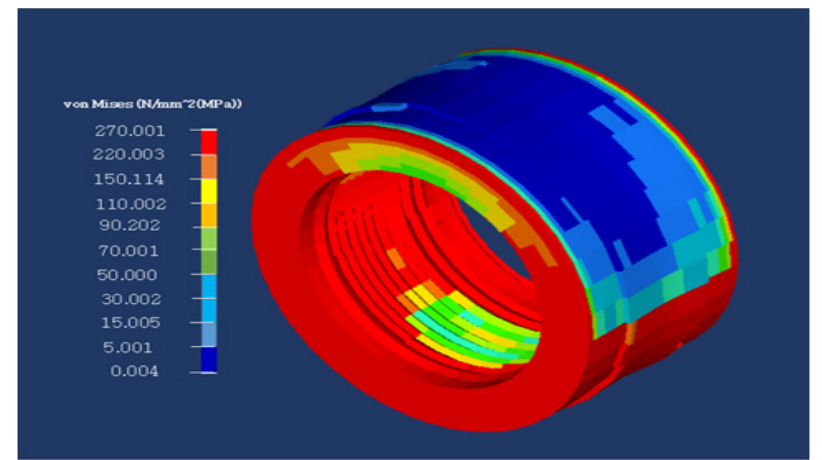

Figure 4 Stress Plot for Aircraft Tire under 77300Kg aircraft Landing Weight. 


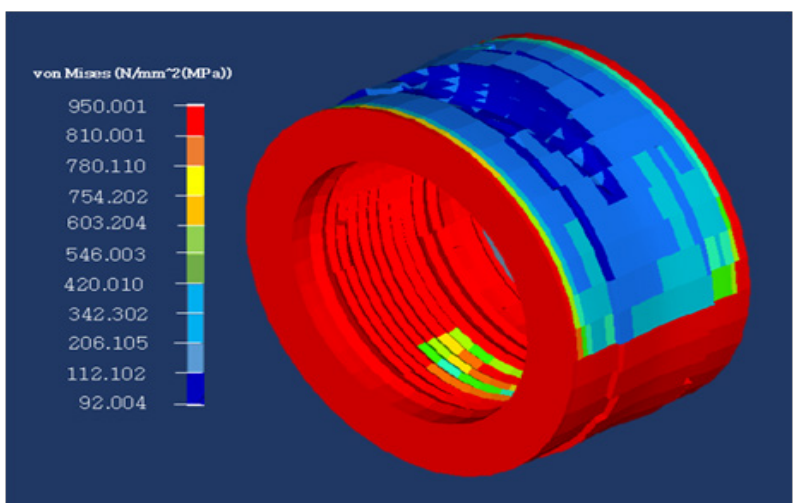

Figure 5 Stress Plot for Aircraft Tire under 90200Kg aircraft Landing Weight.

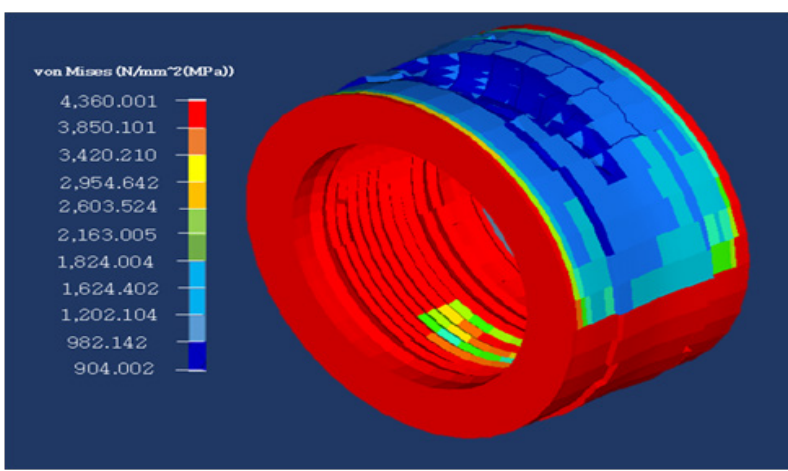

Figure 6 Stress Plot for Aircraft Tire under I I 4000Kg aircraft Landing Weight.

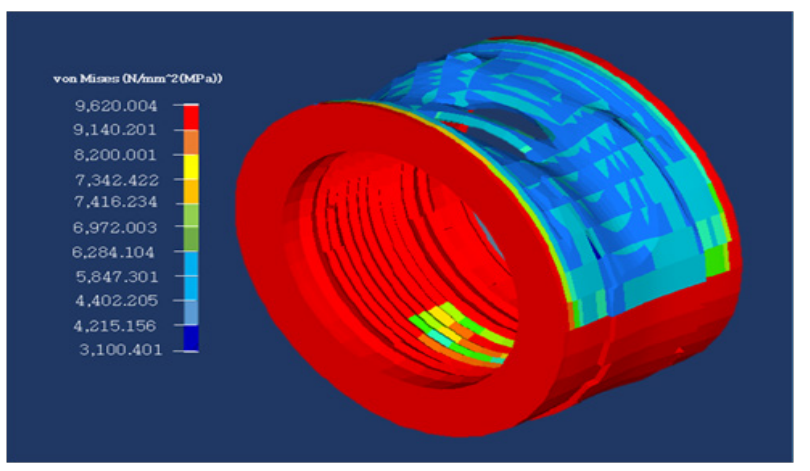

Figure 7 Stress Plot for Aircraft Tire under 126000Kg aircraft Landing Weight.

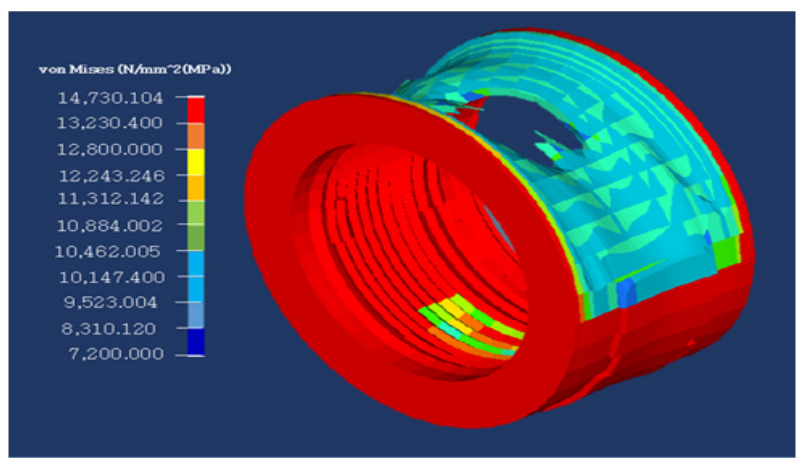

Figure 8 Stress Plot for Aircraft Tire under I34000Kg aircraft Landing Weight.

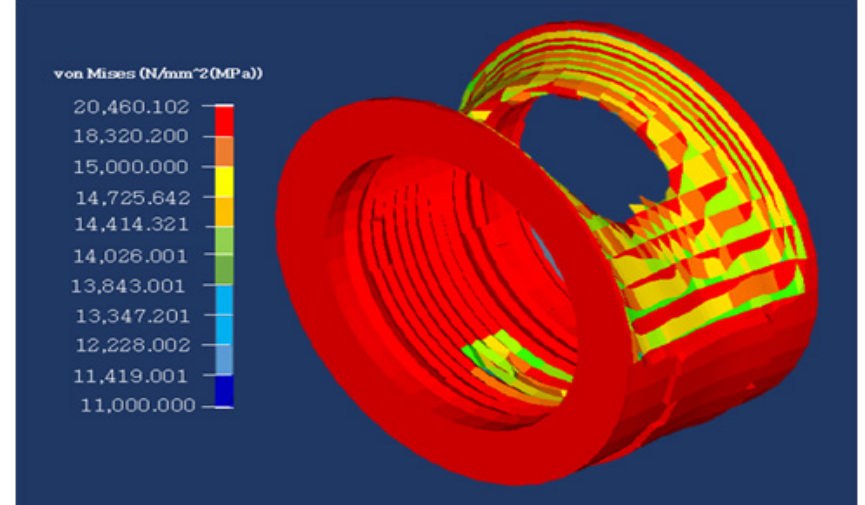

Figure 9 Stress Plot for Aircraft Tire under 150000Kg aircraft Landing Weight.

Table I Maximum and minimum von-mises stress for Tire Model

\begin{tabular}{ccc}
\hline $\begin{array}{c}\text { Aircraft landing } \\
\text { weight (Kg) }\end{array}$ & $\begin{array}{c}\text { Minimum von-mises } \\
\text { stresses (Mpa) }\end{array}$ & $\begin{array}{c}\text { Maximum von-mises } \\
\text { stresses (MPa) }\end{array}$ \\
\hline 77300 & 0 & 270 \\
90200 & 92 & 950 \\
114000 & 904 & 4360 \\
126000 & 3100 & 9620 \\
134000 & 7200 & 14730 \\
150000 & 11000 & 20460 \\
\hline
\end{tabular}

Simulation of the landing phase of an aircraft tyre has been investigated in this study. The trend in the aircraft landing weight and von-mises stress in the tyre indicated that aircraft landing weight is directly proportional to the stress propagations across the tire structure. This is because at the point of landing, the air molecule within the tyre gravitates towards fault lines within the tyre cross-section. Airbus A321NEO maximum aircraft landing weight of $77300 \mathrm{~kg}$ was applied initially on the tire model and the maximum von-mises stress value produced $270 \mathrm{MPa}$ with no visible damage on the tire surface as shown in Figure 4. This implies that the tire model specification can be installed on most aircraft with similar landing weight $(77300 \mathrm{~kg})$. Applying an increased maximum aircraft landing weight of $90200 \mathrm{Kg}$, the tire model produced maximum von-mises stress value of $950 \mathrm{MPa}$ with less visible wearing effect that can be managed as presented in Figure 5. This in some cases may result in partial or complete loss of tread down to tread fabric ply or casing plies as a result of running and/or braking on cross-grooved runways or hydroplaning during landing usually caused by wet or ice-covered runways. With increase of the aircraft landing weight to $114000 \mathrm{Kg}$, the tire model produced maximum von-mises stress of $4360 \mathrm{MPa}$ (shown in Figure 6) with visible cracks on the tread rubber where the joint (splice) separates in a radial (sideways) direction. Tires with this condition should be removed from service to avoid unforeseen accidents. With further increase of the aircraft landing weight to $126000 \mathrm{Kg}$, the tire model produced maximum von-mises stress of $9620 \mathrm{MPa}$ (shown in Figure 7), indicating crack propagation and minimal tearing rate as a result of previous loading conditions. This can result in tread chunking, peeled rib or thrown tread and tire deflation during landing. Increasing the aircraft landing weight to $134000 \mathrm{Kg}$ resulted in excessively high 
von-mises stress of $14730 \mathrm{MPa}$ as shown in Figure 8. This indicated rupture of the tire casing in tread or sidewall area, usually from extremely hard landing or penetration by foreign object. As shown in Figure 9, continuous increase of the aircraft landing weight to $150000 \mathrm{Kg}$ on the tire model produced maximum von-mises stress of $20460 \mathrm{MPa}$, indicating an obvious deformation of the bead wire in the bead toe, face or heel area or possible separation, or void between components in the tread area as a result of loss of adhesion, usually caused by excessive loads or flex heating from under inflation. Figure 10 represents the airbag pressure model for the aircraft tire.

As shown in Figure 10, the final pressure of the tyre was updated from 1.289 to 1.262 tonnes per cubic millimetre. The tyre is inflated gradually from 0 to 1.262 tonnes per cubic millimetre within 0.1 second to help reduce the computational time of the whole model. The pressure is thereafter maintained from that point to ensure that the pressure of the tyre at inflation and after inflation remains constant. At constant pressure the tyre is expected to impact the rigid surface. The final pressure of the simulation of the model after all corrections have been made to the model obtained from previous studies gave a steady increase from 0 till it reaches 1.262 tonnes per cubic millimetre and then remained steady throughout the simulation. The various energy plots for the entire model is presented in Figure 11.

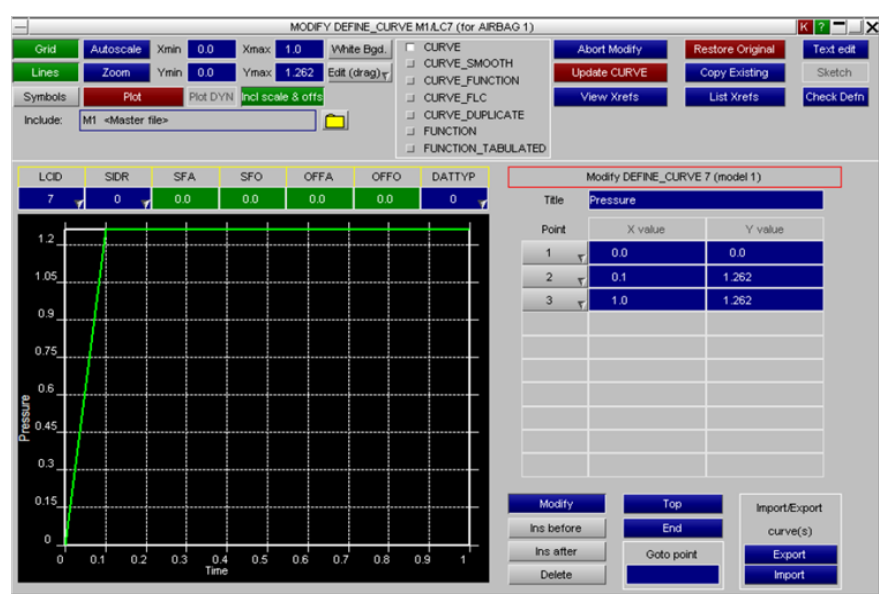

Figure 10 Airbag Pressure model for aircraft tyre.

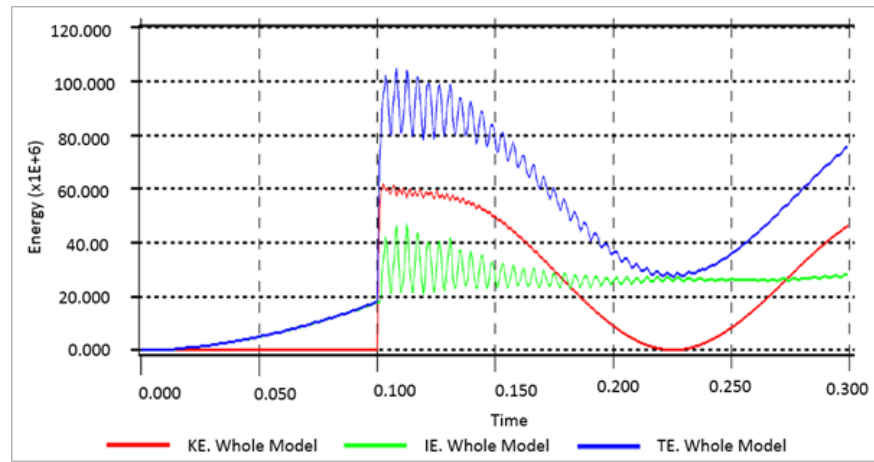

Figure I I Energy Plot for the Tire Model.

To determine if the model is stable, energy distribution plot for Kinetic Energy (KE), internal energy and the Total Energy (TE) was analysed for the tire model. For $0.1 \mathrm{~s}$, the kinetic energy was zero because the tyre was stationary for this period. Within the $0.1 \mathrm{~s}$ the internal energy increases because of the inflation of the tyre. Since total energy is a summation of the kinetic energy and the internal energy, the total energy also increases with the increasing internal energy till it reaches $0.1 \mathrm{~s}$. At this point the tyre begins to move and the kinetic energy increases and the total energy changes with the changing kinetic energy since the internal energy remains somewhat stable for the remaining period of the simulation. The sudden increase in the velocity of the tyre causes a small vibration in the model. Figure 12 represents the maximum landing velocity obtained for the tire model.

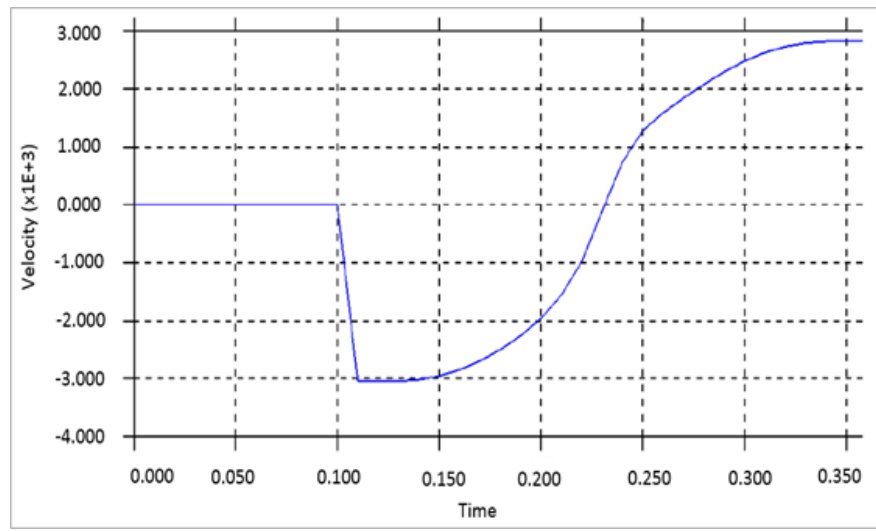

Figure 12 Maximum Landing Velocity obtained for the Tire Model.

The plot of velocity against time shows that the maximum velocity obtained from the simulation by Guo et al. ${ }^{7}$ was $1.5 \mathrm{~m} / \mathrm{s}$ this is way below the stipulated value expected for the impact of an aircraft tyre. After thorough remodelling of the velocity using *PRESCRIBED BOUNDARY MOTION the results obtained from the simulation gave a maximum landing velocity of $2.8 \mathrm{~m} / \mathrm{s}$ of $3.05 \mathrm{~m} / \mathrm{s}$ maximum landing velocity stipulated by EASA standards. With a maximum landing velocity of $2.8 \mathrm{~m} / \mathrm{s}$, there is proximity with the EASA standard compared to $1.5 \mathrm{~m} / \mathrm{s}$ obtained by Guo et al. ${ }^{7}$

\section{Conclusion}

By applying finite element modelling and analysis techniques, a research on the interaction of an aircraft tire with the ground during aircraft landing has been carried out. This study utilized *BOUNDARY_PRESCRIBED_MOTION methods to model the landing scenario of an aircraft at hard landing. Although the $2.8 \mathrm{~m} / \mathrm{s}$ maximum landing velocity for the simulated model was slightly lower than $3.05 \mathrm{~m} / \mathrm{s}$ EASA requirement, the $0.25 \mathrm{~m} / \mathrm{s}$ difference is optimum and can still meet the required performance. The 3-dimensional model developed and analysed have shown the effect of aircraft landing weight on the tire using finite element modelling. Maximum vonmises stress distribution across the tire model for simulated phases of the referenced aircraft landing weight fell between a minimum value of $270 \mathrm{MPa}$ and maximum value of $20460 \mathrm{MPa}$ with minimum aircraft landing weight of $77300 \mathrm{Kg}$ and maximum of $150000 \mathrm{Kg}$ respectively. This indicated that the higher the aircraft landing weight, the more damage the aircraft tire undergoes in terms of stress deformations and build up. Hence, airline operators should note that flying overloaded aircraft can have adverse negative effects on aircraft tire as well as aircraft landing phase. 


\section{Acknowledgements}

The authors of this manuscript would like to express their gratitude to Coventry University for providing the tools (used in achieving the objectives of this study) and guidance in terms of tutorial classes.

\section{Conflict of interest}

None.

\section{References}

1. Michelin Aircraft Tire Care and Service Manual for Aircraft Tires and Tubes. Michelin: France; 2011.

2. Shannon A. Aircraft Payload-Range Analysis for Financiers. Aircraft Monitor, Version 1.0, 2013.

3. Ajoy KK. Aircraft Design. 1st ed. Cambridge University Press: UK; 2010 .

4. Daidzic NE, Shrestha J. Airplane landing performance on contaminated runways in adverse conditions. Journal of Aircraft. 2008;45(6):2131-2144.

5. Bastien C, Guo H, Blundell MV. A Methodology to Optimize the Mass of an Aircraft Tire through FEA Modeling. Coventry University: UK; 2015.

6. Lin S, Gu L. Influence of crosslink density and stiffness on mechanical properties of type I collagen gel. Materials. 2015;8(2):551-560.

7. Guo H, Bastien C, Blundell M, et al. Development of a detailed aircraft tyre finite element model for safety assessment. Materials \& Design. 2014;53:902-909.
8. Persson B. Rubber friction: role of the flash temperature. J Phys Condens Matter. 2006;18(32):7789-7823.

9. Reid AC. Development and Optimization of a Wide Base Fea Truck Tire Model for Prediction of Tire-Road Interactions. University of Ontario Institute of Technology: Ontario; 2015.

10. Alroqi AA, Wang W. A Comparison of Aircraft Tire Skid With Initial Wheel Rotational Speed Using ANSYS Transient Simulation. International Journal of Mechanical and Production Engineering. 2016; 4(1):127-131.

11. Feeler RA. Managing Aircraft-tire Wear and Damage Requires Adherence to Removal Limits. Flight Safety Foundation: Aviation Mechanics Bulletin, May-June 1999.

12. Reid JD, Boesch DA, Bielenber RW. Detailed Tyre Modelling for Crash Applications. International Journal of Crashworthiness. 2007;12(5):521-529.

13. Yaohua W, Guofeng L, Zhibin W. A new test study on measurement of bias aircraft tire blowout. Advances in Mechanical Engineering. 2017;9(4):1-9.

14. Alroqi AA, Wang W. Comparison of Aircraft Tire Wear with Initial Wheel Rotational Speed. International Journal of Aviation, Aeronautics and Aerospace. 2015;2(1):1-28.

15. A321neo: The most Efficient Single-aisle Jetliner. Airbus; 2018.

16. Bjorkmon M. Evaluation of finite element tools for transient structural dynamic simulations of firing systems. Chalmers University of Technology: Goteborg; 2010. 